\title{
Desenvolvimento de um sistema de fachada ventilada com placas cerâmicas de grês porcelanato voltado para a construção civil do Brasil
}

\section{(Development of a ventilated façade system with porcelainized stoneware tiles directed to the Brazil's civil construction)}

\author{
A. Müller, O. E. Alarcon \\ LABMAT, Campus Universitário, Trindade, Depto. de EMC, Bloco B, UFSC, C.P. 476 \\ Florianópolis, SC 88040-900 \\ alexanmuller@zipmail.com.br,orestes@materiais.ufsc.br
}

\begin{abstract}
Resumo
No presente estudo buscou-se desenvolver e analisar um protótipo de sistema de fixação de placas cerâmicas de grês porcelanato em fachada ventilada a partir de tecnologia existente no país. Além disso, procurou-se analisar aspectos como os efeitos da operação de execução de furos no material cerâmico, além de propriedades relacionadas com a interação das placas cerâmicas com parafusos expansores para fixação, como torque máximo no aperto destes parafusos e resistência da união entre parafusos e placas. Desta forma, desenvolveu-se um procedimento para execução de furos nãopassantes nas placas cerâmicas, onde os parafusos expansores são inseridos. Análise utilizando microscópio eletrônico de varredura mostrou que na operação de execução dos furos são introduzidas ranhuras e abertos poros na superficie dos furos. Desenvolveram-se metodologias de ensaio para determinação de propriedades tais como torque máximo no aperto dos parafusos expansores para fixação das placas cerâmicas e resistência da união entre estes parafusos expansores e placas cerâmicas. No painel do protótipo de fachada ventilada, executado em uma edificação nas condições reais (Tijucas, SC, próximo a Florianópolis - latitude $27^{\circ} 03$ 'S, longitude $48^{\circ} 45^{`} \mathrm{~W}$ ), não se verificaram patologias durante um período de análise visual de aproximadamente 2 anos.
\end{abstract}

Palavras-chave: fachada ventilada, grês porcelanato, construção civil.

Abstract

The aim of the present study is to develop and analyze a prototype of porcelainized stoneware tiles fixing system in ventilated façade based on existing technology in the country. Moreover, the aim is to analyze aspects as the effects of holes execution operation in the ceramic material, besides properties related to the interaction of the tiles with expander screws for their fixation, as maximum torque for tightening these screws and union strength between screws and tiles. In this way, a procedure for no-pass holes execution in the tiles was developed, where the expander screws are inserted. Analysis using scanning electron microscopy shows that grooves are introduced and pores are opened in holes surface with the operation of holes execution. Testing methodologies for determining properties such as maximum torque for tightening of the expander screws for tiles fixing and union strength between these expander screws and tiles were developed. In the panel of the ventilated façade prototype, executed in a building in the real conditions (Tijucas, SC, near to Florianópolis - latitude 2703'S, longitude $48^{\circ} 45^{\prime} \mathrm{W}$ ), it was not verified pathologies during a visual analysis period of approximately 2 years.

Keywords: ventilated façade, porcelainized stoneware, civil construction.

\section{INTRODUÇÃO}

O sistema de revestimento externo de edificações denominado fachada ventilada caracteriza-se pela existência de ventilação em uma câmara de ar, como se percebe no esquema do sistema mostrado na Fig. 1. Origina-se um fluxo de ar ascendente com o aquecimento deste no interior da câmara. Além disso, diferenças de pressão no interior da câmara de ar ventilada, devido à ação do vento, também contribuem para a ventilação [1].

Osistemaderevestimento de fachada ventiladaéempregado em outros países, como os europeus, onde há empresas que exploram este mercado e possuem tecnologias de execução para o sistema. No Brasil, o sistema de revestimento de fachada ventilada ainda é pouco utilizado. No entanto, pode-se desenvolver um sistema de fachada ventilada apropriado para utilização no Brasil, a partir de tecnologia existente no país. Assim, pode-se explorar as vantagens do sistema, dentre as quais destaca-se a melhoria do isolamento térmico da fachada de edificações. Além disso, o sistema possibilita a utilização de placas cerâmicas de grandes dimensões em fachadas; a restauração de fachadas, uma nova tecnologia para emprego de grês porcelanato além de pisos, etc.

No sistema de fachada ventilada podem ser empregados diferentes materiais de revestimento tais como placas cerâmicas, placas de pedra natural (mármore, granito), etc., normalmente em grandes dimensões [2]. Na fixação dos revestimentos à parede externa são utilizados componentes 


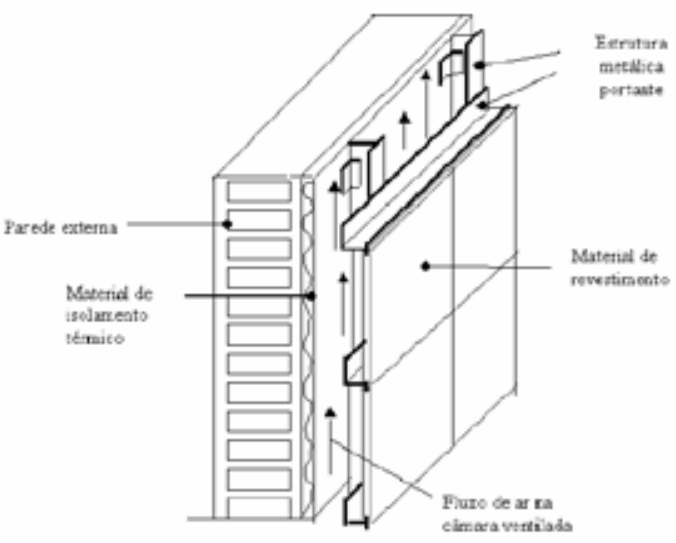

Figura 1: Esquema do sistema de revestimento de fachada ventilada.

[Figure : Scheme of the ventilated façade covering system.]

metálicos inoxidáveis. Especificamente, na fixação de placas cerâmicas em fachadas ventiladas emprega-se uma estrutura metálica portante (Fig. 1), sendo que esta estrutura é ancorada à parede externa usando, por exemplo, parafusos chumbadores [3]. Reuter [4] trata especificamente sobre as exigências em relação à ancoragem na parede externa em sistemas de fachada ventilada.

Existem alguns sistemas empregados em outros países, como Itália e Alemanha, para fixação de placas cerâmicas em fachadas ventiladas. Há necessidade de execução de entalhes ou furos nas placas cerâmicas para inserção de dispositivos de fixação que não sejam aparentes, de modo que podem ser introduzidos defeitos que prejudiquem a resistência mecânica do material. Os dispositivos de fixação podem ser também mais simples e ficarem aparentes, de modo que as placas cerâmicas são apenas encaixadas nos dispositivos.

Estes sistemas de fixação de placas cerâmicas em fachadas ventiladas são encontrados principalmente em catálogos de produtos de empresas de outros países. A literatura científica e tecnológica é escassa em relação a estudos mais aprofundados sobre estes diferentes sistemas de fixação de placas cerâmicas em fachadas ventiladas. Na literatura existente não são encontrados procedimentos de ensaio detalhados e estudos sobre propriedades importantes destes sistemas de fixação como união entre dispositivos de fixação e material cerâmico, resistência mecânica dos materiais cerâmicos com furos ou cortes, etc.

A norma alemã DIN 18516: Teil 1 [5] estabelece considerações gerais em relação ao projeto, as cargas atuantes, as variações volumétricas, a execução do sistema de fachada ventilada e a realização de ensaios. As exigências para o projeto e a execução de sistema de fachada ventilada com placas de pedra natural ou placas de concreto são estabelecidas em normas tais como a DIN 18516: Teil 3 [6] e DIN 18516: Teil 5 [7], respectivamente. Aspectos construtivos do sistema de fachada ventilada com a utilização de placas cerâmicas como material de revestimento também são descritos por Fliesen und Platten [8]. Segundo Karl [9], o revestimento de fachadas de edificações com placas cerâmicas de grandes dimensões é uma tecnologia moderna que se consolidou na construção civil em países europeus, originando novas possibilidades nas fachadas de edificações quando comparada com a utilização de placas em menores dimensões.

No presente estudo, busca-se desenvolver e analisar um protótipo de sistema de fixação de placas cerâmicas de grês porcelanato em fachada ventilada, a partir de tecnologia existente no país. Além disso, analisar aspectos fundamentais neste protótipo de sistema de fachada ventilada como os efeitos da operação de execução de furos cilíndricos não-passantes no material cerâmico, além de propriedades como torque máximo no aperto dos parafusos expansores desenvolvidos para fixação das placas cerâmicas e união entre estes parafusos expansores e placas cerâmicas.

\section{MATERIAIS E MÉTODOS}

Inicialmente, concebeu-se um protótipo de sistema para fixação de placas cerâmicas de grês porcelanato em fachada ventilada. Para tanto, se procedeu a análise de possíveis formas de fixação e a viabilidade de desenvolvimento a partir da tecnologia disponível no país, considerando-se aspectos como materiais e equipamentos disponíveis; exigências construtivas; etc. Optou-se por um sistema simples com furos cilíndricos não-passantes na parte posterior das placas e nos quais são inseridos parafusos expansores não-aparentes, para acoplamento adequado, e utilizando-se ainda um adesivo estrutural anaeróbico, para que haja aderência adequada.

Procedeu-se análise da superfície do material cerâmico no interior dos furos (3 placas), utilizando microscópio eletrônico de varredura. Para isto, foram obtidas amostras da região do fundo e das laterais dos furos, bem como de região próxima aos furos na superfície do tardoz das placas cerâmicas, para comparação com a superfície do material no interior dos furos.

Além disso, desenvolveu-se um procedimento de ensaio para a determinação do torque máximo aplicável no aperto dos parafusos expansores (10 placas). Utilizouse torquímetro na realização do ensaio, além de empregarse um suporte que fixa as placas cerâmicas em nível sobre uma bancada. Determinou-se ainda a resistência da união entre parafusos expansores e placas cerâmicas (10 placas), utilizando-se equipamento automático, constituído de um tripé regulável ligado a uma célula de carga por um pistão automático (Fig. 2). Foi necessário o desenvolvimento de um adaptador metálico para prender os parafusos expansores à rosca do parafuso do equipamento. Os parafusos expansores foram fixos às placas cerâmicas (aperto de $0,15 \mathrm{kgf} . \mathrm{m}$ ) e aguardou-se durante quatro dias até a realização do ensaio para que houvesse o desenvolvimento de uma aderência adequada. Utilizou-se uma placa cerâmica auxiliar e duas placas cerâmicas cortadas em dimensões menores para apoiar o tripé e distribuir a carga. A velocidade de aplicação da carga foi de $0,02 \mathrm{kN} / \mathrm{s}$. 


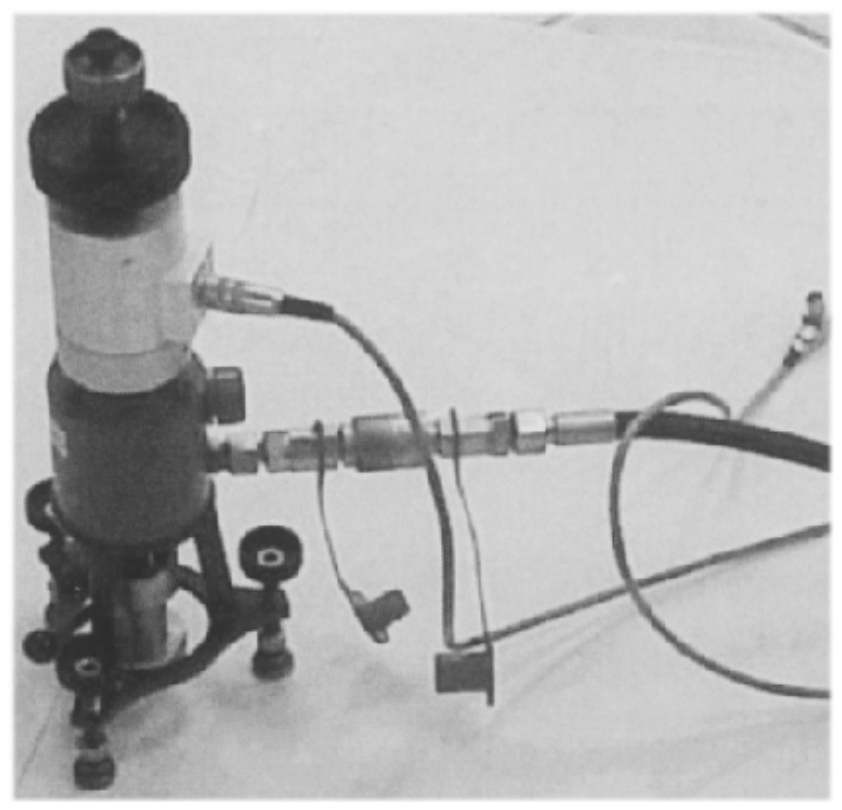

Figura 2: Tripé regulável ligado à célula de carga por pistão automático.

[Figure 2: Adjustable tripod linked to load cell by automatic piston.]

\section{RESULTADOS E DISCUSSÃO}

\section{Desenvolvimento do protótipo do sistema de fachada ventilada}

O protótipo de sistema de fixação desenvolvido no presente estudo inclui a execução de furos cilíndricos não-passantes na região dos quatro vértices das placas cerâmicas. Para tanto, foi desenvolvido um procedimento para execução destes furos com a utilização de broca cilíndrica diamantada de diâmetro adequado às dimensões dos parafusos expansores empregados, as quais

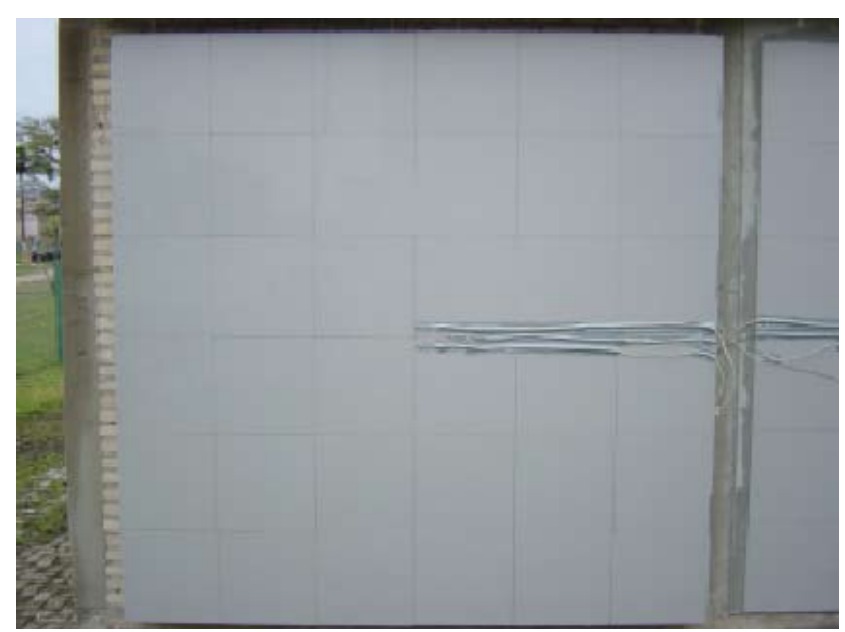

Figura 3: Modo de inserção dos parafusos expansores nos furos das placas cerâmicas.

[Figure 3: Insertion way of the expander screws in the tile holes] são usadas na perfuração de mármore e granito. Na execução dos furos nas placas cerâmicas pode-se utilizar furadeira de bancada, como a utilizada no presente estudo.

$\mathrm{O}$ modo de inserção dos parafusos expansores nos furos cilíndricos não-passantes das placas cerâmicas é demonstrado no esquema da Fig. 3. Os parafusos expansores para fixação das placas cerâmicas foram adaptados a partir de parafusos chumbadores. Estes parafusos de fixação possuem expansor lateral metálico na extremidade que é inserida nos furos das placas. Contudo, pode-se produzir industrialmente parafusos expansores voltados especificamente para o sistema de fachada ventilada.

O princípio de acoplamento destes parafusos de fixação consiste na expansão lateral no interior dos furos nas placas cerâmicas, à medida que a porca dos parafusos é apertada. Ressalta-se também o emprego do adesivo estrutural anaeróbico no sistema de fixação desenvolvido para garantir a aderência entre os parafusos expansores e as placas cerâmicas.

O sistema de fixação desenvolvido é constituído ainda por barras horizontais e verticais produzidas a partir de chapas de aço inoxidável dobradas e cortadas, as quais constituem a estrutura portante das placas cerâmicas. No entanto, pode-se aperfeiçoar esta estrutura metálica e utilizar barras de alumínio, que apresentam menor peso específico. Na Fig. 4 tem-se um detalhe da vista lateral do protótipo de fachada ventilada executado no presente estudo (painel de 269,5x269,5 cm²) e que mostra os componentes da estrutura metálica. Este painel foi executado em uma edificação, em condições reais, na cidade de Tijucas, SC, próximo a Florianópolis - latitude $27^{\circ} 03^{\prime} \mathrm{S}$, longitude $48^{\circ} 45^{\prime} \mathrm{W}$. Um aspecto importante deste protótipo de sistema de fixação é que os componentes foram desenvolvidos a partir de materiais de fácil obtenção no mercado brasileiro e de tecnologias simples.

Em relação ao aspecto estético do protótipo de sistema de fachada ventilada desenvolvido, na Fig. 5 é mostrada a vista frontal geral do painel executado. Devem ser observados

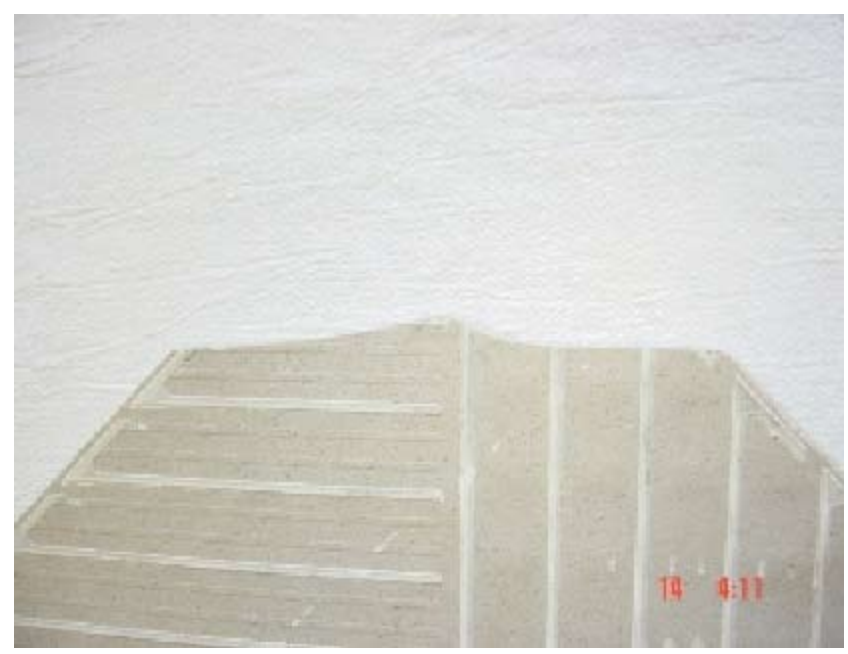

Figura 4: Detalhe da vista lateral da estrutura metálica portante das placas cerâmicas.

[Figure 4: Detail of lateral view of tiles supporting metallic structure.] 
com atenção aspectos como prumo, nível e alinhamento na execução do sistema de fachada ventilada, principalmente na fixação das barras metálicas verticais à parede externa da edificação. Em relação às juntas, foram deixados espaços abertos de 1,0 mm entre as placas cerâmicas, utilizando-se espaçadores de aço inoxidável. Para fachadas com maiores dimensões seria necessário deixar juntas sem os espaçadores entre painéis de aproximadamente $3,0 \times 3,0 \mathrm{~m}^{2}$, devido às variações dimensionais das placas cerâmicas decorrentes das variações de temperatura e da expansão por umidade.

O sistema desenvolvido para fixação de placas cerâmicas

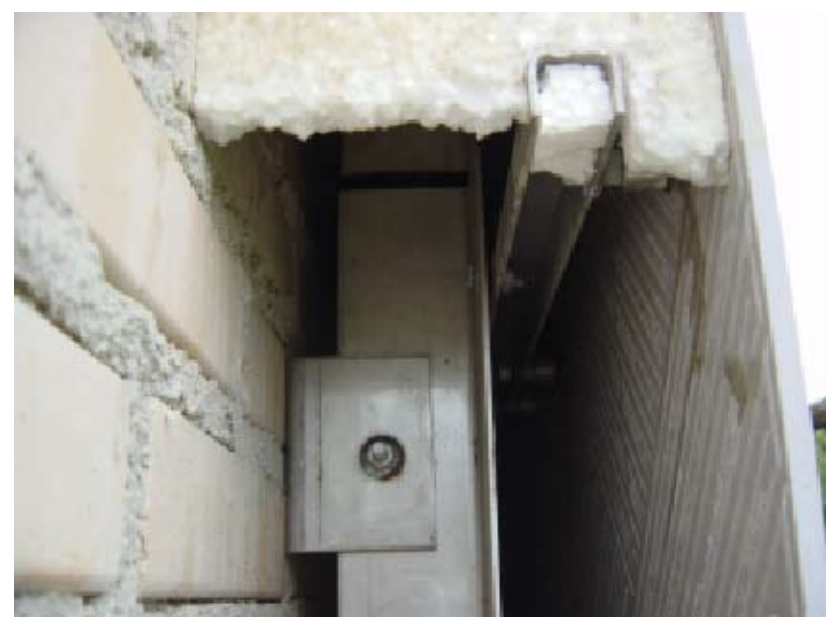

Figura 5: Vista frontal geral do painel do protótipo de fachada ventilada. [Figure 5: General frontal view of the ventilated façade prototype panel.]

de grês porcelanato em fachada ventilada demonstrou ser viável em relação à execução. Além disso, constatou-se que o conjunto do protótipo do sistema desenvolvido apresentou um comportamento adequado frente às solicitações reais na fachada da edificação. Procedendo-se análise visual da fachada, durante um período aproximado de dois anos, não se constatou a ocorrência de quaisquer tipos de patologias.

\section{Análise da superficie do material cerâmico no interior dos furos}

Os resultados obtidos na análise da superfície no interior dos furos e no tardoz de três diferentes placas cerâmicas foram similares, de modo que se selecionaram algumas imagens obtidas. Na Fig. 6a tem-se uma visão geral da superfície normal de uma região do tardoz das placas cerâmicas de grês porcelanato. Percebe-se que a superfície do tardoz das placas apresenta uma textura granular saliente. Na Fig. 6b visualiza-se mais claramente a morfologia da superfície do tardoz das placas cerâmicas, evidenciando a textura granular. Percebe-se, ainda, a existência de quantidade significativa de poros superficiais. Alguns poros maiores apresentam dimensões de até aproximadamente $0,13 \mathrm{~mm}$.

Em relação à morfologia superficial no interior dos furos
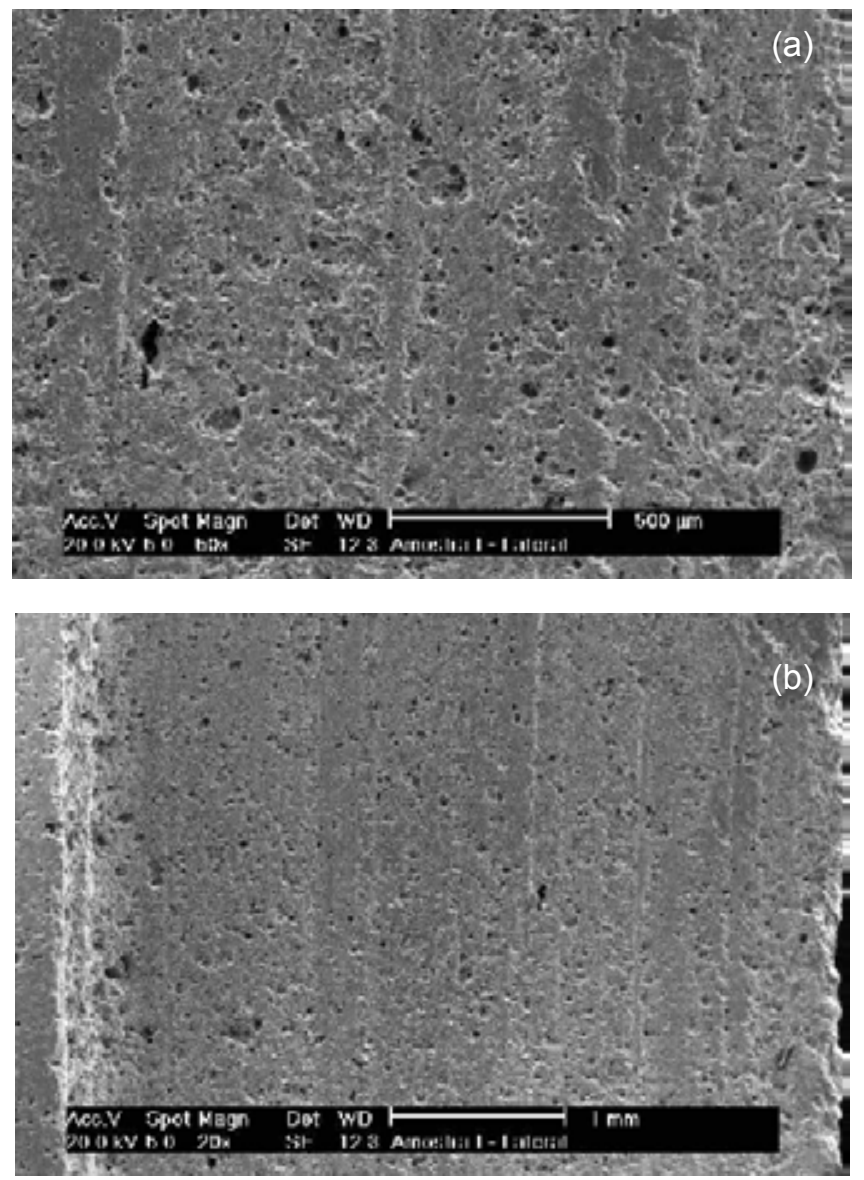

Figura 6: Micrografias obtidas em MEV observando região da superfície do tardoz das placas cerâmicas: (a) aumento de 25 X (b) aumento de $100 \mathrm{X}$.

[Figure 6: SEM micrographs observing tiles backside surface region: (a) $25 \mathrm{X}$ increase (b) $100 \mathrm{X}$ increase.]

das placas cerâmicas, na Fig. 7a mostra-se a região central da superfície do fundo do furo analisado. Ficam saliências no fundo dos furos em decorrência da geometria da broca diamantada usada na execução dos furos, a qual apresenta no seu topo uma fenda. A morfologia da superfície destas saliências é mostrada na Fig. 7b. Constata-se uma morfologia significativamente mais regular que a superfície do tardoz, sem a presença de grânulos salientes bem evidentes. Além disso, percebe-se uma quantidade significativa de poros de dimensões inferiores a $0,1 \mathrm{~mm}$ na superfície destas saliências.

A Fig. 8a mostra uma visão geral das ranhuras originadas na superfície do fundo dos furos, na região próxima à saliência no centro. Constata-se a presença de ranhuras concêntricas, cuja origem está associada aos grãos de diamante presentes na extremidade da broca diamantada. Estes grãos de diamante ficam salientes no topo em relação ao material que constitui a matriz da broca devido ao desgaste. Tais ranhuras representam um defeito superficial a nível macroscópico no material cerâmico. Percebe-se ainda que há uma quantidade significativa de poros no fundo do furo de dimensões inferiores a 0,1 mm, mas há alguns maiores de dimensões de 

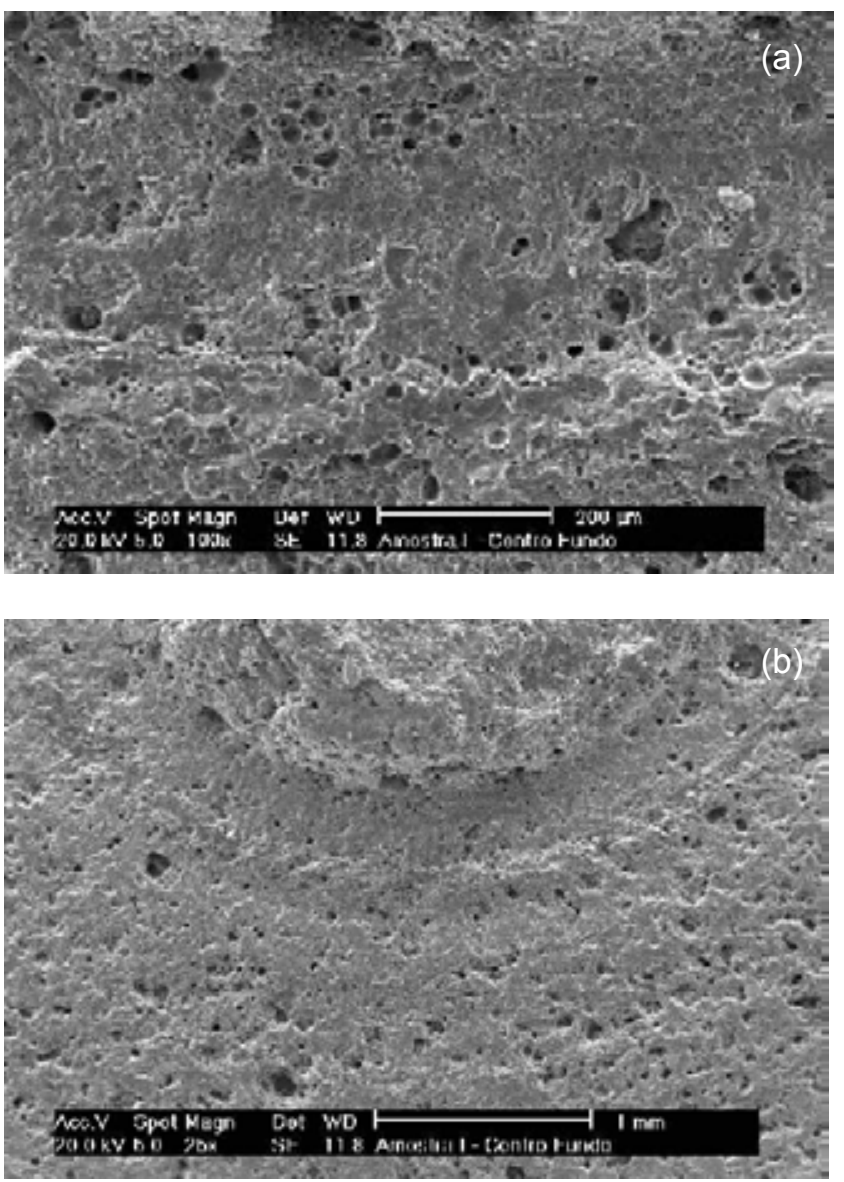

Figura 7: Micrografias obtidas em MEV observando saliência na região central da superfície do fundo de um furo: (a) aumento $20 \mathrm{X}$ (b) aumento $100 \mathrm{X}$.

[Figure 7: SEM micrographs observing salience in a central region of hole deep surface: (a) $20 \mathrm{X}$ increase (b) $100 \mathrm{X}$ increase.]

até aproximadamente $0,15 \mathrm{~mm}$.

Analisando-se mais detalhadamente a região do fundo dos furos próxima à saliência, visualiza-se na Fig. $8 \mathrm{~b}$ uma ranhura caracterizada por um desnível entre as regiões de cima da figura, mais baixa, e a região de baixo da figura que é mais alta. A largura desta ranhura é aproximadamente $0,3 \mathrm{~mm}$. Constata-se a presença de quantidade significativa de poros de dimensões inferiores a $0,1 \mathrm{~mm}$. A morfologia da superfície apresenta-se mais regular que no tardoz das placas cerâmicas.

Aexplicação para a ocorrência desta quantidade substancial de poros na superfície das ranhuras e de todo o fundo dos furos é principalmente a remoção de camadas do material cerâmico que expõe os poros fechados na superfície, na operação de execução dos furos. A morfologia da superfície de ranhuras no fundo dos furos próximas às paredes laterais mostrou-se similar a verificada na região anterior.

A Fig. 9a mostra uma região das paredes laterais dos furos nas placas cerâmicas. Na extremidade esquerda da figura aparece a superfície do fundo dos furos e na extremidade direita aparece a superfície do tardoz das placas cerâmicas. Percebe-se que as ranhuras são menos evidentes que as ranhuras existentes
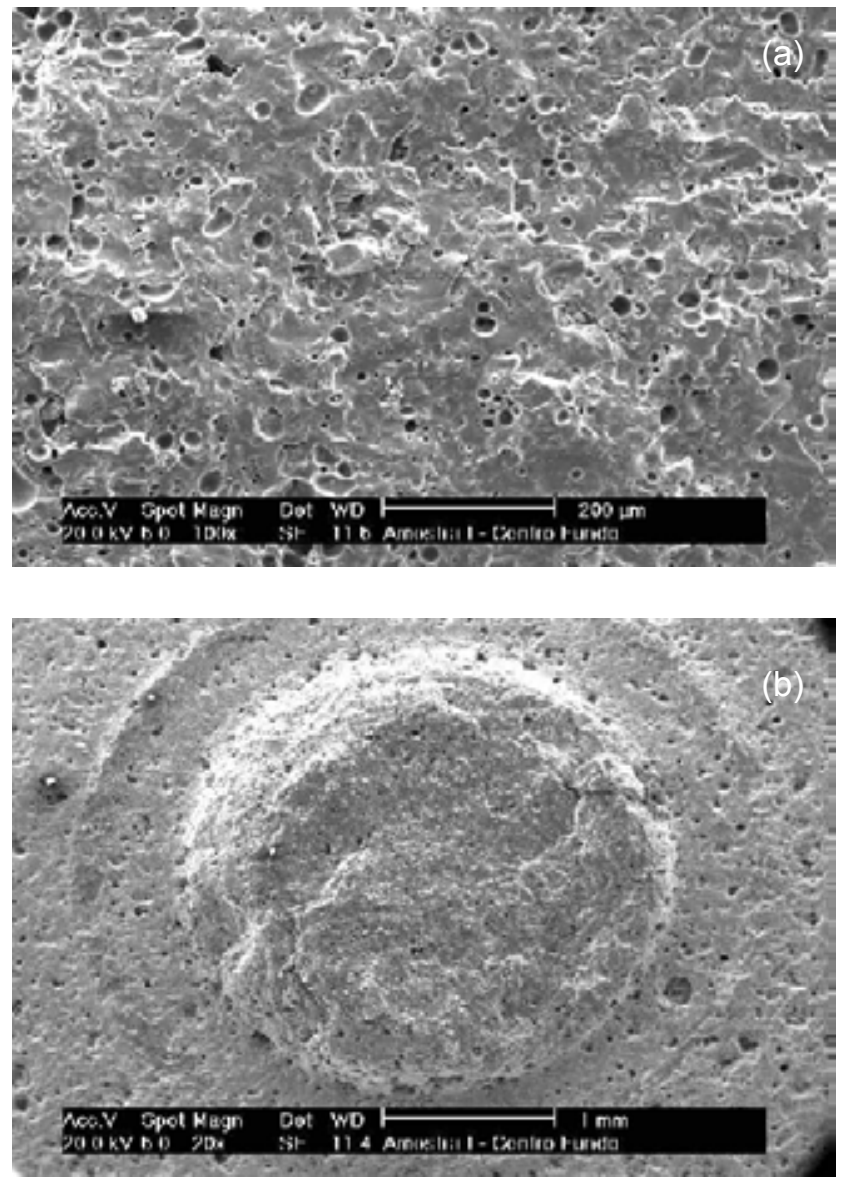

Figura 8: Micrografias obtidas em MEV observando o fundo de um furo [(a) aumento $25 \mathrm{X}]$ e as ranhuras próximas à saliência [(b) aumento $100 \mathrm{X}]$.

[Figure 8: SEM micrographs observing a hole deep [(a) $25 X$ increase] and grooves near to the salience [(b) $100 \mathrm{X}$ increase].

no fundo dos furos. A superfície das paredes laterais dos furos apresenta uma quantidade significativa de poros, tal como na superfície do fundo dos furos. Algumas ranhuras nas paredes laterais dos furos, na região mais próxima da superfície do tardoz, são mostradas em detalhe na Fig. 9b. A morfologia das ranhuras localizadas em outra região das paredes laterais dos furos, mais próximos ao fundo destes, mostrou-se similar a da região mostrada na Fig. $9 b$.

Constata-se mais claramente a quantidade significativa de poros na superfície das paredes laterais dos furos, tal como no fundo dos furos. Alguns destes poros apresentam dimensões maiores de até $0,17 \mathrm{~mm}$, no entanto em sua maioria apresentam dimensões inferiores a $0,1 \mathrm{~mm}$. Além disso, as ranhuras demonstram-se menos evidentes que aquelas verificadas no fundo dos furos, o que é coerente com a magnitude substancialmente maior da pressão exercida no fundo dos furos na execução destes do que a exercida nas paredes laterais. Isto contribui para um maior desgaste no topo da broca diamantada e para que os grãos de diamante sejam expostos de forma mais significativa nesta região, originando ranhuras mais evidentes. 

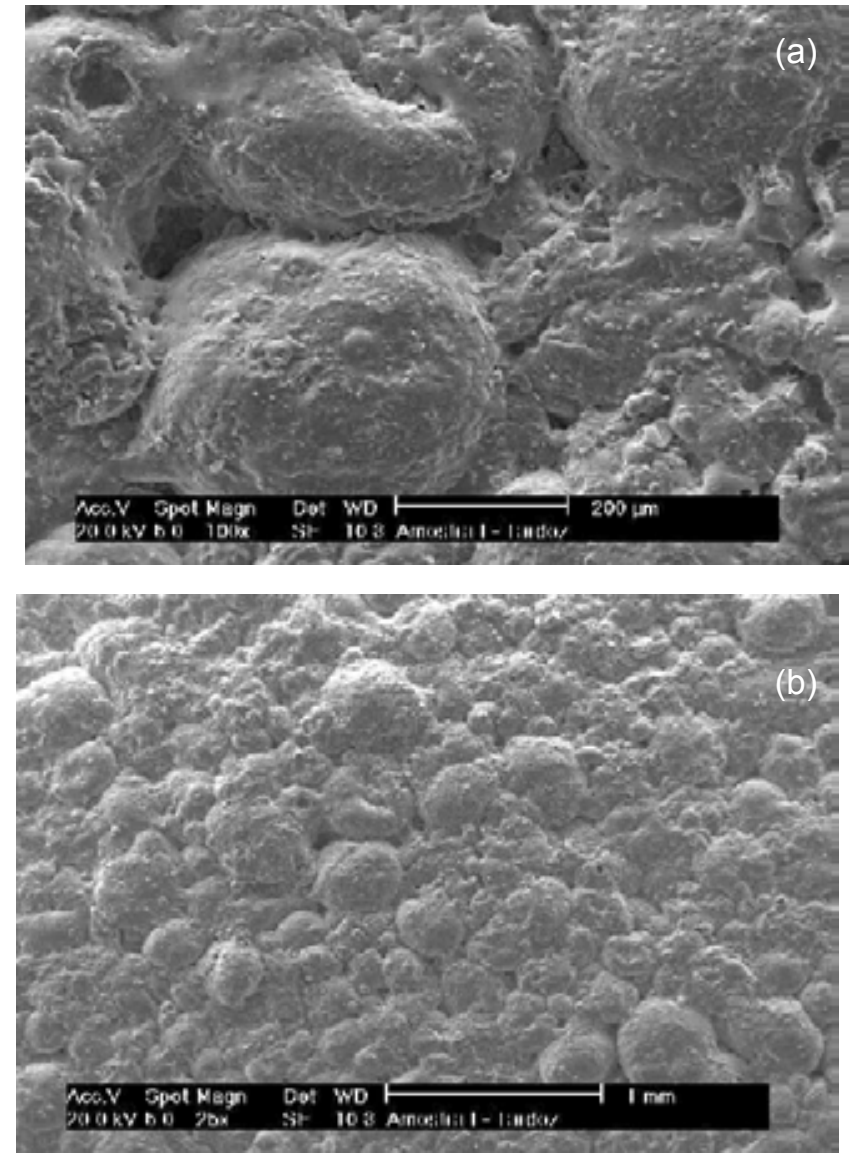

Figura 9: Micrografia obtida em MEV observando as paredes laterais de um furo e as ranhuras: (a) aumento $20 \mathrm{X}$ (b) aumento $50 \mathrm{X}$. [Figure 9: SEM micrographs observing a hole lateral walls and the grooves: (a) $20 \mathrm{X}$ increase (b) $50 \mathrm{X}$ increase.]

\section{Torque máximo no aperto dos parafusos expansores}

Os valores obtidos no ensaio para verificação do torque máximo no aperto dos parafusos expansores, mostrados na Tabela I, são utilizados para a determinação do valor a ser utilizado no aperto dos parafusos e acoplamento destes com as placas cerâmicas. $\mathrm{O}$ valor adotado no presente estudo para aperto dos parafusos expansores foi de $0,15 \mathrm{kgf.m}(1,47 \mathrm{~N} . \mathrm{m})$, o qual é aproximadamente a metade do torque máximo médio ( 0,31 kgf.m - 3,04 N.m) e garante uma margem de segurança substancial em relação ao menor valor de torque máximo verificado, o qual foi de $0,25 \mathrm{kgf.m}(2,45 \mathrm{~N} . \mathrm{m})$.

Os valores individuais de torque máximo correspondem a valor constante de torque aplicado que se estabelecia a partir de determinado momento no ensaio dos parafusos expansores, após o qual continuava-se a apertar a porca dos parafusos sem que houvesse mudança nos valores mostrados pelo torquímetro. A perda da capacidade de aperto dos parafusos ocorreu de modo que estes se desprendiam do interior dos furos, e para que isso ocorresse eram necessárias em média 3,6 voltas completas da porca do parafuso após estabelecer-se o patamar constante de torque aplicado.
Tabela I - Resultados de torque máximo no aperto dos parafusos expansores.

[Table I - Results of maximum torque in the expander screw tightening.]

\begin{tabular}{cc}
\hline & Torque (kgf.m) \\
\hline Média & 0,31 \\
Mínimo & 0,25 \\
Desvio Padrão & 0,04 \\
Coeficiente de Variação (\%) & 12,79 \\
\hline
\end{tabular}

\section{Resistência da união entre parafusos expansores e placas} cerâmicas

Os resultados obtidos no ensaio são mostrados na Tabela II. A ruptura ocorreu nas placas cerâmicas, não se verificando ruptura especificamente na interface entre placas cerâmicas e parafusos de fixação.

Não foram verificados quaisquer problemas em relação à união das placas cerâmicas com os parafusos expansores no painel do protótipo do sistema de fachada ventilada executado na edificação, demonstrando que o modo de fixação desenvolvido mostrou-se eficiente nas condições reais existentes. A solicitação máxima devido à sucção do vento no painel do protótipo de fachada ventilada é estimada em 39,0 N (4,0 kgf) por parafuso, segundo cálculos baseados na norma NBR 6123 [10] e nos coeficientes de redução da ação do vento em fachadas ventiladas [11]. Esta solicitação apresenta um valor baixo em função da pequena área das placas cerâmicas utilizadas no presente estudo, contudo para placas maiores aumentam os esforços oriundos da sucção devido ao vento. A ruptura de todas as placas cerâmicas ocorreu aproximadamente da mesma forma, caracterizando-se por ruptura nos vértices das placas durante a aplicação da carga para arrancar os parafusos expansores. A superfície de fratura nas placas cerâmicas apresentou, aproximadamente, a orientação mostrada na Fig. 10, passando pelo interior dos furos.

Tabela II - Resultados de resistência da união entre parafusos expansores e placas cerâmicas (carga de ruptura das placas). [Table II - Results of union strength between expander screws and tiles (tiles rupture load).]

\begin{tabular}{cc}
\hline & Carga de ruptura (N) \\
\hline Média & 900,7 \\
Mínimo & 712,0 \\
Desvio Padrão & 121,2 \\
Coeficiente de Variação (\%) & 13,5 \\
\hline
\end{tabular}

\section{CONCLUSÕES}

Obtiveram-se resultados satisfatórios em relação ao desenvolvimento de protótipo de sistema para fixação de placas cerâmicas de grês porcelanato em fachada ventilada. 


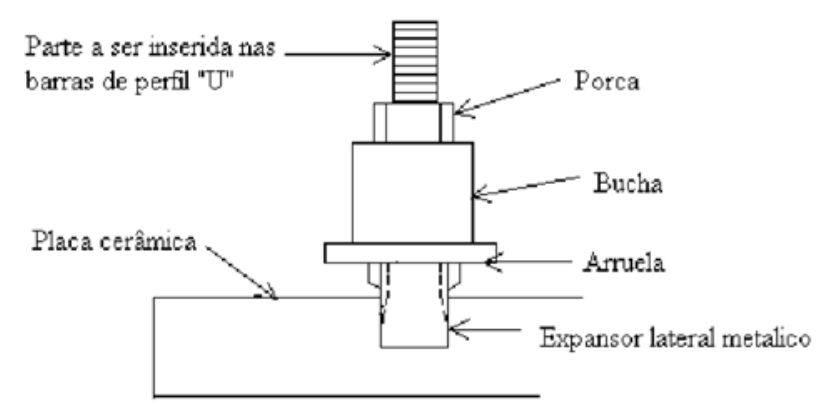

Figura 10: Forma de ruptura das placas cerâmicas no ensaio de resistência da união entre parafusos expansores e placas cerâmicas.

[Figure 10: Ceramic tiles rupture manner in the test of union strength between expander screws and tiles.]

Desenvolveu-se um procedimento para execução de furos cilíndricos não-passantes na região dos vértices das placas cerâmicas, bem como parafusos expansores que são acoplados no interior destes furos e colados com adesivo estrutural anaeróbico. Desenvolveu-se ainda uma estrutura metálica portante para as placas cerâmicas. Todos os componentes foram desenvolvidos a partir de materiais de fácil obtenção no mercado brasileiro e de tecnologias simples.

Naoperaçãode execuçãodosfuroscilíndricosnão-passantes nas placas cerâmicas de grês porcelanato são introduzidas ranhuras com larguras que variam aproximadamente entre $0,3 \mathrm{~mm}$ e $0,4 \mathrm{~mm}$ no fundo dos furos. A origem das ranhuras está associada às partículas de diamante da broca que ficam salientes no topo à medida que a matriz que as envolve vai se desgastando. As ranhuras são menos perceptíveis nas paredes laterais dos furos, em virtude da menor pressão exercida nesta região dos furos durante a operação de execução destes. Além disso, são abertos poros na superfície dos furos, tanto no fundo como nas paredes laterais, na maioria com dimensões inferiores a $0,1 \mathrm{~mm}$. Contudo, constatam-se alguns poros de dimensões de até aproximadamente $0,17 \mathrm{~mm}$. Estes poros são originados na execução dos furos em virtude, principalmente, da remoção de camadas de material cerâmico, de modo que os poros fechados ficam expostos na superfície.

Desenvolveu-seumametodologiadeensaioparadeterminar o torque máximo no aperto dos parafusos expansores para o acoplamento destes com as placas cerâmicas. Os resultados do ensaio mostram que a perda de capacidade de aperto ocorre nos parafusos expansores. A partir dos resultados do ensaio pode-se estabelecer o valor de torque a ser aplicado no aperto dos parafusos expansores na execução da fachada ventilada, que no presente estudo foi de $0,15 \mathrm{kgf} . \mathrm{m}(1,47$ N.m). Este valor representa aproximadamente a metade do torque máximo médio $[0,31 \mathrm{kgf.m}(3,04 \mathrm{~N} . \mathrm{m})]$ e garante uma margem de segurança substancial em relação ao menor valor de torque máximo, ou seja, 0,25 kgf.m (2,45 N.m).

A resistência da união entre parafusos expansores e placas cerâmicas foi determinada a partir de procedimento de ensaio desenvolvido no presente estudo. O valor mínimo de carga de ruptura obtido no ensaio foi de 712,0 N (72,6 kgf), ou seja, a resistência mínima da união entre parafusos expansores e placas cerâmicas. A ruptura ocorreu nos vértices das placas cerâmicas, não se verificando ruptura na interface entre parafusos expansores e placas cerâmicas. Não se verificaram problemas relacionados à união entre parafusos expansores $\mathrm{e}$ placas cerâmicas no painel do protótipo de fachada ventilada, demonstrando que o modo de fixação desenvolvido foi eficiente nas condições reais existentes. A solicitação máxima devido à sucção do vento atuante no painel de fachada ventilada é estimada em 39,2 N (3,96 kgf) por parafuso, cujo valor é baixo devido à pequena área das placas cerâmicas utilizadas no presente estudo.

O comportamento estrutural do conjunto dos componentes da fachada ventilada mostrou-se adequado frente às solicitações atuantes, como vento, variações de temperatura e de umidade, etc. Analisando-se visualmente, durante um período aproximado de dois anos, não foram verificadas patologias.

\section{REFERÊNCIAS}

[1] Schweizer Ingenieur und Architekt, Bauphysik der hinterlüfteten fassade, Schweizer Ingenieur und Architekt 103, 44 (1985) 1107.

[2] J. Hoffmann, W. Meyer-Bohe, Fachadas: forma y detalle de paredes y revestimientos exteriores, Editora Blume, Barcelona (1974).

[3] IEMB - Institut für Erhaltung und Modernisierung von Bauwerken, Hinweise zum standardleistungsbuch für das bauwesen. Bauen im bestand (BiB) block- und plattenbau. Leistungsbereich 502: vorgehängte hinterlüftete fassaden, Editora Beuth, Berlim (1998).

[4] M. Reuter, Befestigung hinterlüfteter

Fassadenkonstruktionen,

Bauingenieur 73, 2 (1998) A16.

[5] DIN - Deutsches Institut für Normung, DIN 18516, Teil 1: Außenwandbekleidungen, hinterlüftet: Anforderungen, Prüfgrundsätze, Berlim (1999).

[6] DIN - Deutsches Institut für Normung, DIN 18516, Teil 3: Außenwandbekleidungen, hinterlüftet: Naturwerkstein. Anforderungen, Bemessung, Berlin (1990).

[7] DIN - Deutsches Institut für Normung, DIN 18516, Teil 5: Außenwandbekleidungen, hinterlüftet: Betonwerkstein; Anforderungen, Bemessung. Berlin (1999).

[8] Fliesen und Platten, Konstruktionen mit fliesenbelägen. Außenwandkonstruktionen - vorgehängte hinterlüftete fassaden. Tl.II, Fliesen und platten 38, 2 (1988) 48.

[9] A. Karl, Keramische Fassaden, Keramik-Grossplatten für vorgehängte, hinterlüftete Aussenwandbekleidungen, Deutsches architektenblatt 29, 11 (1997) 1699.

[10] ABNT - Associação Brasileira de Normas Técnicas, NBR 6123: forças devidas ao vento em edificações, Rio de Janeiro (1988).

[11] U. Peil, R. Egner, Zur windbelastung hinterlüfteter Fassadenelemente, Bauingenieur 69, 3 (1994) 109.

(Rec. 06/12/2004, Ac. 06/05/2005) 